\title{
No Increase in Breast Cancer Risk in Japanese Women Taking Oral Contraceptives: a Case-Control Study Investigating Reproductive, Menstrual and Familial Risk Factors for Breast
} Cancer

\author{
Miho Ichida ${ }^{1,2 *}$, Akemi Kataoka ${ }^{1}$, Ruriko Tsushima ${ }^{1}$, Tetsuya Taguchi ${ }^{2}$
}

\begin{abstract}
Background: Low-dose oral contraceptives (OC) were approved by the Japanese Ministry of Health, Labor and Welfare in 1999, yet despite their contraceptive and non-contraceptive health benefits, only $5 \%$ of the target population use them. Fear of increased cancer risk, particularly breast cancer, is one reason for this. Due to low $\mathrm{OC}$ uptake and low screening participation, a paucity of data is available on the risk of $\mathrm{OC}$ use and breast cancer in Japanese women. The present study investigated $\mathrm{OC}$ use and breast cancer risk, as well as menstrual, reproductive and family factors. Materials and Methods: This was a clinic-based case-control study of women aged 20-69yrs who had undergone breast screening between January 2007 and December 2013 in central Tokyo. In all, $28.8 \%$ of the participants had experience with $O C$ use. Cases were 155 women with a pathologically confirmed diagnosis of breast cancer. Controls were the remaining 12,333 women. Results: Increased age was a significant risk factor for breast cancer $(\mathbf{p}<0.001)$. A lower risk was found in premenopausal women presently taking OC compared to never users (OR 0.45; 95\% CI 0.22-0.90) after adjusting for age, parity and breast feeding, and a family history of breast cancer. Conclusions: Increased age rather than $\mathrm{OC}$ use had a greater effect on breast cancer risk. This risk may be decreased in premenopausal women with $\mathrm{OC}$ use, but further long-term prospective studies are necessary.
\end{abstract}

Keywords: Oral contraceptives - breast cancer risk - case-control study - Japanese women

Asian Pac J Cancer Prev, 16 (9), 3685-3690

\section{Introduction}

Since the late 1960s, the number of women using oral contraceptives (OC) has increased in accordance with changes in women's lifestyle. According to a recent survey by the United Nations, in the UK (2008-09), France (2008) and the United States (2006-10), 28.0\%, $40.6 \%$ and $16.3 \%$ of women were using OC. In India (2007-08), however, it was only 3.6\% (United Nations, 2013). Combined estrogen and progesterone OC became available in 1957 in Japan. While licensed for menstrual disorder, off-license use included contraception. Lowdose oral contraceptives, however, were not approved by the Japanese Ministry of Health, Labor and Welfare until 1999, almost 40 years later than most other countries. One year after their introduction only $1.9 \%$ and $0.7 \%$ of married and unmarried women, respectively, were reported to be using them (Matsumoto et al., 2003). In 2012, more than 13 years since their introduction, this had only increased to $5.0 \%$ of the target population and $3.4 \%$ for married women (Kitamura, 2014), which is still considerably lower than in many other western countries.
Guidelines on the appropriate use of OC and HRT, as well as solving the problem of low uptake of OC belong to the field of gynecology in Japan. However, for breast surgeons and oncologists, the issue of how prescribing $\mathrm{OC}$ to young women of reproductive age affects their future risk of breast cancer is a pressing one that needs to be elucidated urgently. From a logical point of view, while HRT is a therapy to replenish levels of estrogen and progesterone, OC help balance levels of both hormones and maintain normal levels, or constant levels that are lower than normal, and from this aspect, while many breast cancers are associated with female hormones, it is difficult to conceive that using OC would increase the risk of breast cancer.

However, the 2013 version of the Japanese Breast Cancer Society's Therapeutic Guidelines for Breast Cancer state that OC use may increase the risk of developing breast cancer (the level of evidence is limited but suggestive). Despite this no consensus was reached regarding period of use, previous use and composition of the drug and the risk of breast cancer. In contrast, the section on breast cancer in the 2004 amended guidelines 
Miho Ichida et al

for OC use published by the Japan Society of Obstetrics and Gynecology, states that an increased risk of breast cancer has not been found in OC users compared to nonOC users, and this includes no difference in those with a familial history of breast cancer, length of use, age at first use, type of hormone and amount used. It concludes with the statement that no increased risk of breast cancer mortality with OC use has been found regardless of duration of use and recommends that patients are told that the possibility of OC increasing breast cancer risk is small. While inconsistencies exist in the stance of both these academic associations, the data referred to is not only based on that of Japanese women, but also on previous studies in non-Asian populations. Since the history of OC use in Japan is relatively limited compared to other countries, extensive studies on OC use and breast cancer risk, such as a meta-analysis, do not exist. There is only one prospective study from the Tohoku region with comprehensive data (Kawai et al., 2010), which concludes that no association exists between OC use and breast cancer incidence. However, only $6.0 \%$ of the participants in the study had experience of OC and only $12(4.8 \%)$ of the 248 women who developed breast cancer had taken OC, so the sample size was extremely small. Therefore, while various studies have investigated body weight (Mori et al., 2011; Suzuki et al., 2011; Minatoya et al., 2014), attendance at breast screening (Tsunematsu et al., 2013), smoking (Nishino et al., 2014), alcohol consumption (Suzuki et al., 2010), diet (Suzuki et al., 2013; Wada et al., 2013) and the risk of breast cancer in Japanese women, there is a paucity of data on OC use and the risk of breast cancer.

At our institution, while most of the patients are enrolled in the local government funded breast cancer screening program, we also have many private patients, since our clinic focuses on women's health care. Of these private patients, $28.8 \%$ are also using (or have used) OC, thus we are in a unique position to be able to investigate OC use and breast cancer risk in Japanese women. Therefore, in the present study, the aim was to examine OC use and breast cancer risk from the data of a clinicbased case-control study.

\section{Materials and Methods}

\section{Study population}

The study population was all women aged 20-69 years who had undergone private opportunistic screening for breast cancer between January 2007 and December 2013 at a clinic in central Tokyo. Patient charts were reviewed and the results of the patients' most recent screening test were used. Cases were 155 patients who had a pathologically confirmed diagnosis of breast cancer. Controls were 12,223 patients who had undergone breast screening and had no finding of breast cancer.

\section{Screening method and cancer diagnosis}

For all women a clinical breast examination was performed. For women $>40 y$ rs, both ultrasound and mammography were strongly recommended. However, the choice was left to the woman herself. When abnormalities were detected and further tests deemed necessary, they

Table 1. Distribution of Cases and Controls according to selected Characteristics and Risk Factors for breast Cancer

\begin{tabular}{|c|c|c|c|c|c|c|}
\hline \multirow[t]{2}{*}{ Factor } & \multirow{2}{*}{$\begin{array}{c}\text { Total } \\
(\mathrm{n}=12378)^{\mathrm{a}} \\
\mathrm{N}\end{array}$} & \multicolumn{2}{|c|}{$\begin{array}{c}\text { Cases } \\
(n=155)\end{array}$} & \multicolumn{2}{|c|}{$\begin{array}{c}\text { Controls } \\
(\mathrm{n}=12223)\end{array}$} & \multirow[t]{2}{*}{$\mathrm{p}$ value $^{\mathrm{b}}$} \\
\hline & & $\mathrm{N}$ & $\%$ & $\mathrm{~N}$ & $\%$ & \\
\hline \multicolumn{7}{|l|}{ Age (yrs) } \\
\hline $20-29$ & 1455 & 6 & 3.9 & 1449 & 11.9 & \\
\hline $30-39$ & 5496 & 24 & 15.5 & 5472 & 44.8 & \\
\hline $40-49$ & 3528 & 70 & 45.2 & 3458 & 28.3 & \\
\hline $50-59$ & 1514 & 44 & 28.4 & 1470 & 12 & \\
\hline $60-69$ & 385 & 11 & 7.1 & 374 & 3.1 & $<0.001$ \\
\hline Age $($ mean \pm SD $)$ & $39.6 \pm 9.2$ & $46.1 \pm 8.6$ & $39.5 \pm 9.2$ & & & \\
\hline \multicolumn{7}{|l|}{ OC use } \\
\hline Never & 8817 & 119 & 76.8 & 8698 & 71.2 & \\
\hline Ever & 3561 & 36 & 23.2 & 3525 & 28.8 & 0.13 \\
\hline \multicolumn{7}{|l|}{ Menopausal status } \\
\hline Premenopause & 10533 & 106 & 73.1 & 10427 & 87.8 & \\
\hline Postmenopause & 1488 & 39 & 26.9 & 1449 & 12.2 & $<0.001$ \\
\hline \multicolumn{7}{|l|}{ Parity } \\
\hline Parous & 3299 & 53 & 35.1 & 3246 & 26.8 & \\
\hline Nulliparous & 8967 & 98 & 64.9 & 8869 & 73.2 & $0.02 *$ \\
\hline \multicolumn{7}{|c|}{ Breast-feeding (among parous women) } \\
\hline Never & 222 & 5 & 9.8 & 217 & 7.2 & \\
\hline Ever (Breast and bottle) & 2067 & 34 & 66.7 & 2033 & 67 & \\
\hline Ever (Breast only) & 796 & 12 & 23.5 & 784 & 25.8 & 0.74 \\
\hline \multicolumn{7}{|c|}{ Family history of breast cancer (BC) } \\
\hline No & 10405 & 128 & 82.6 & 10227 & 84.1 & \\
\hline Yes (not first degree relative) & 1172 & 14 & 9.0 & 1158 & 9.5 & \\
\hline Yes (first degree relative) & 801 & 13 & 8.4 & 788 & 6.4 & 0.62 \\
\hline
\end{tabular}

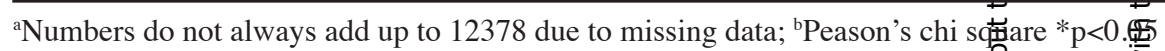


No Increase in Breast Cancer Risk in Japanese Women Taking Oral Contraceptives: a Case-Control Study

were covered by the patients' health insurance. Intramammary lesions were further investigated by fine needle aspiration cytology or needle biopsy to give a definite diagnosis of breast cancer. In some cases, when additional specific testing or treatment was necessary, women were referred to other institutions where the diagnosis was made and the authors received a written pathological report regarding the stage and type of breast cancer.

\section{Assessment of breast cancer risk factors}

All patients at our institution undergoing breast cancer screening are asked to complete a questionnaire on past or present exogenous hormone use (OC, HRT, others) as well as the duration of use, number of pregnancies, parity, history of breast-feeding and familial history of breast cancer at their first visit. For women who had been prescribed $\mathrm{OC}$ at our institution, patient charts were analyzed to investigate ever use, period of use and type of OC.

\section{Statistical analyses}

Data were analyzed using SPSS statistical software version 19 (SPSS Inc., Chicago, USA). In Table 1, Pearson's chi-square test was used to investigate the association between breast cancer incidence and exogenous hormone use, as well as menstrual, reproductive factors and familial factors. In Table 2, logistic regressions analyses were conducted for unadjusted estimations and age-adjusted estimations. In Table 3, to further investigate
OC use and breast cancer risk, participants were stratified by menopausal status and past, present or never use of OC was analyzed. All estimations were adjusted for age, parity and breast-feeding, and family history of breast cancer. As a new variable, parity and breast-feeding was combined to avoid multi-collinearity, and not to reduce samples. We also investigated past and present OC use compared to never having taken OC. In Tables 2 and 3, all relevant odds ratios (OR) and 95\% confidence intervals (CI) were calculated. To investigate the risk of breast cancer according to menopausal status and ever (never, past and present) OC use, further estimations were performed. In all analyses, statistical significance was defined as a 2-tailed p-value of $<0.05$.

\section{Ethical Consideration}

All women attending our clinic for the first time are asked whether they consent to their anonymized data being used for research purposes. Only those women who gave their informed written consent were included in the study. Almost all women gone their informed written consent. The study design was approved by the Institutional Review Board at the clinic where the study took place. No financial incentive was given for participation in the study.

\section{Results}

The main characteristics of the 155 cases and 12,223 controls according to selected characteristics and risk

Table 2. Logistic Regression Analysis of Selected Characteristics and Risk Factors for Breast Cancer

\begin{tabular}{|c|c|c|c|c|c|}
\hline & \multirow[t]{2}{*}{ Case/ Controls } & \multicolumn{2}{|c|}{ Unadjusted } & \multicolumn{2}{|c|}{ Age Adjusted } \\
\hline & & OR & $(95 \% \mathrm{CI})$ & OR & $(95 \% \mathrm{CI})$ \\
\hline \multicolumn{6}{|l|}{$\overline{\text { Age (yrs) }}$} \\
\hline $20-29$ & $6 / 1449$ & 1 & & & \\
\hline $30-39$ & $24 / 5472$ & 1.06 & $(0.43-2.60)$ & & \\
\hline $40-49$ & $70 / 3458$ & 4.89 & $(2.12-11.28)$ & & \\
\hline $50-59$ & $44 / 1470$ & 7.23 & $(3.07-17.02)$ & & \\
\hline $60-69$ & $11 / 374$ & 7.10 & $(2.61-19.33)$ & & \\
\hline \multicolumn{6}{|c|}{$\mathrm{p}$ trend $<0.001$} \\
\hline \multicolumn{6}{|l|}{ OC use } \\
\hline Never & $119 / 8698$ & 1 & & 1 & \\
\hline Ever & $36 / 3525$ & 0.75 & $(0.51-1.09)$ & 0.76 & $(0.52-1.11)$ \\
\hline \multicolumn{6}{|l|}{ Menopausal status } \\
\hline Premenopause & $106 / 10427$ & 1 & & 1 & \\
\hline Postmenopause & $39 / 1449$ & 2.65 & $(1.83-3.84)^{* *}$ & 0.87 & $(0.48-1.59)$ \\
\hline \multicolumn{6}{|l|}{ Parity } \\
\hline Parous & $53 / 3246$ & 1.48 & $(1.06-2.07)^{*}$ & 0.68 & $(0.47-0.98)^{*}$ \\
\hline Nulliparous & $98 / 8869$ & 1 & & 1 & \\
\hline \multicolumn{6}{|c|}{ Breast-feeding (among parous women) } \\
\hline Never(bottle only) & $5 / 217$ & 1 & & 1 & \\
\hline Ever(Breast and bottle) & $34 / 2033$ & 0.73 & $(0.28-1.88)$ & 0.81 & $(0.31-2.11)$ \\
\hline Ever(Breast only) & $12 / 784$ & 0.66 & $(0.23-1.91)$ & 0.86 & $(0.30-2.49)$ \\
\hline \multicolumn{6}{|l|}{ Parity \& Breast-feeding } \\
\hline Nulliparous & $98 / 8869$ & 1 & & 1 & \\
\hline Never(bottle only) & $5 / 217$ & 1.26 & $(0.35-4.56)$ & 0.83 & $(0.33-2.11)$ \\
\hline Ever(Breast and bottle) & $34 / 2033$ & 0.87 & $(0.41-1.89)$ & 0.68 & $(0.44-1.03)$ \\
\hline Ever(Breast only) & $12 / 784$ & 0.14 & $(0.42-3.08)$ & 0.71 & $(0.38-1.32)$ \\
\hline \multicolumn{6}{|l|}{ Family history of breast cancer } \\
\hline No & $128 / 10227$ & 1 & & & 1 \\
\hline Yes (not first degree relative) & $14 / 1158$ & 0.97 & $(0.56-1.69)$ & 1.02 & $(0.59-1.79)$ \\
\hline Yes (first degree relative) & $13 / 788$ & 1.33 & $(0.75-2.35)$ & 1.30 & $(0.73-2.31)$ \\
\hline
\end{tabular}


Table 3. Multivariate Logistic Regression Analysis for Breast Cancer According to Ever use of OC and Menopausal Statusa

\begin{tabular}{|c|c|c|c|c|c|c|c|c|c|}
\hline & \multirow[t]{2}{*}{ Case/Controls } & \multicolumn{2}{|c|}{$\begin{array}{c}\text { Estimation } 1 \\
\text { All samples } \\
(n=12378)\end{array}$} & \multirow[t]{2}{*}{ Case/Controls } & \multicolumn{2}{|c|}{$\begin{array}{c}\text { Estimation } 2 \\
\text { Premenopausal } \\
(n=10533)\end{array}$} & \multirow[t]{2}{*}{ Case/Controls } & \multicolumn{2}{|c|}{$\begin{array}{c}\text { Estimation } 3 \\
\text { Postmenopausal } \\
(n=1488)\end{array}$} \\
\hline & & OR & $(95 \% \mathrm{CI})$ & & OR & $(95 \% \mathrm{CI})$ & & OR & $(95 \% \mathrm{CI})$ \\
\hline \multicolumn{10}{|l|}{ OC use } \\
\hline Never & $119 / 8698$ & 1 & & $81 / 7290$ & 1 & & $34 / 1217$ & 1 & \\
\hline Ever & $36 / 3525$ & 0.72 & $(0.49-1.07)$ & $25 / 3137$ & 0.65 & $(0.41-1.02)$ & $5 / 232$ & 0.71 & $(0.24-2.06)$ \\
\hline \multicolumn{10}{|l|}{ OC past use } \\
\hline Never & $119 / 8698$ & 1 & & $81 / 7290$ & 1 & & $34 / 1217$ & 1 & \\
\hline Past & $16 / 1084$ & 0.84 & $(0.49-1.46)$ & $8 / 842$ & 0.68 & $(0.32-1.42)$ & $4 / 185$ & 0.88 & $(0.30-2.55)$ \\
\hline Present & $12 / 1706$ & 0.51 & $(0.27-0.96)^{*}$ & $9 / 1604$ & 0.45 & $(0.22-0.90)^{*}$ & $1 / 21$ & $\mathrm{NA}^{\mathrm{b}}$ & \\
\hline Missing & $8 / 735$ & & & $8 / 691$ & & & $0 / 26$ & & \\
\hline
\end{tabular}

${ }^{\mathrm{a}}$ Adjusted for age, parity and breast feeding and family history of breast cancer; ${ }^{\mathrm{b}}$ Not applicable. The coefficient could not be calculated due to the low number of cases in this category; ${ }^{*} \mathrm{p}<0.05$

factors for breast cancer are shown in Table 1 . In total 12,378 women had attended for screening and 155 (1.3\%) were diagnosed with breast cancer. The mean age of the control group (39.5 \pm 9.2$)$ was significantly lower than the cases (46.1 \pm 8.6$)$. Being postmenopausal was associated with the high risk of breast cancer $(\mathrm{p}<0.001)$ with $26.9 \%(n=39)$ of the breast cancer cases having reached menopause compared to only $12.2 \%(n=1,449)$ of the controls. Interestingly, parity did not confer protection against breast cancer, instead it associated with the risk with $35.1 \%(n=53)$ of the cases having given birth to at least one child, compared to only $26.8 \%(n=3,246)$ of the controls $(\mathrm{p}=0.02)$. OC use, breast-feeding history, family history and breast cancer or having a first degree relative with breast cancer were not significant.

Logistic regression analyses of selected characteristics and risk factors for breast cancer are shown in Table 2. As expected, an increase in age was significantly associated with an increase in breast cancer ( $p$ trend $<0.001$ ), with this increase in risk rising sharply after women had reached the age of $40 \mathrm{yrs}$. OR and $95 \% \mathrm{CI}$ for women in their $40 \mathrm{~s}$, $50 \mathrm{~s}$ and $60 \mathrm{~s}$ were 4.89 (2.12-11.28); 7.23 (3.07-17.02); and 7.10 (2.61-19.33), respectively, compared to women aged under $30 y r s$. OC use was negatively associated with a high risk of breast cancer, however, it was not statistically significant. Menopause was a risk in the unadjusted model (OR 2.65; 95\%CI 1.83-3.84), however this risk disappeared when adjusted for age (OR 0.87 ; 95\%CI $0.48-1.59)$. While parity significantly correlated with the risk of breast cancer in the unadjusted model (OR 1.48 95\% CI 1.06-2.07), a protective association was found after adjusting for age (OR 0.68; 95\%CI 0.47-0.98). Having a family history of breast cancer was not significant a risk for breast cancer in either model.

Table 3 shows the results of three estimations by multivariate logistic regression analyses. In Estimation 1 , OC ever use was not associated with a significantly lower risk of breast cancer compared to women who had never used OC. Compared to OC past use, presently taking OC was also significantly linked to a lower risk of breast cancer (OR 0.51; 95\%CI 0.27-0.96). Estimation 2 showed similar results to Estimation 1. No significant negative or positive association was found in the postmenopausal group (Estimation 3). Though OC past use showed significant associations in two estimations, OC use did not confer any significant increased risk in breast cancer in any of the estimations.

\section{Discussion}

Despite the non-contraceptive health benefits from $\mathrm{OC}$ such as a reduction in menorrhagia, irregular menses, functional ovarian cysts, benign breast disease, dysmenorrhea, premenstrual tension and iron-deficiency anemia (Caserta et al., 2014), fear from increased cancer risk is one of the most significant reasons for low acceptance of this reliable contraceptive method in Japanese women, as well as low compliance. However, due to low participation in breast cancer screening and low uptake of OC use, there is a paucity of data on breast cancer risk and OC use in this population. To better understand this risk we conducted a case control study of 12,378 Japanese women aged between 20 and $69 \mathrm{yrs}$, attending a clinic in central Tokyo.

The potential association between OC use and breast cancer has been investigated in many epidemiological studies, both in Asian (Kawai et al., 2010; Anothaisintawee et al., 2014; Vaisy et al., 2014) and non-Asian populations (1996; Marchbanks et al., 2002; Kahlenborn et al., 2006) with often conflicting results. In a clinic-based crosssectional study by Anothaisintawee et al (Anothaisintawee et al., 2014) that investigated risk factors for breast cancer in Thai women, present OC use was associated with a 4.6 fold risk of breast cancer (OR 4.58; 95\%CI 2.16-9.71), but not past use. In the multivariate model used in the aforementioned study, BMI was also adjusted for. No information on BMI was available in the present study, which might explain the difference in result. A similar, but slightly smaller risk (OR 3.72; 95\%CI 1.84-5.11) was found by Vaisy et al in their hospital based study of Iranian women (Vaisy et al., 2014). However, the risk was only significant with high dose estrogen OC (OR 2.83; 95\%CI 1.62-4.93). For low dose OC statistical significance disappeared (OR1.18; 95\%CI 0.82-1.70). Since almost all the women in this study used low dose OC only, this may explain the difference in the results. Similarly, the results of a recent prospective cohort study of American nurses that investigated OC and all-cause mortality, found 
premature mortality due to breast cancer (test for trend $\mathrm{p}<0.0001)$. However, as with the previous study the results pertained to earlier oral contraceptive formulations with higher hormone doses (Charlton et al., 2014) and not low dose OC such as those used in this study.

In the only other large scale study to investigate OC use and the risk of breast cancer in Japanese women, as with the results obtained in this study, an increased risk was not found (OR 0.80; 95\%CI 0.45-1.44) (Kawai et al., 2010). However, as mentioned in the introduction, only $5.96 \%$ of the participants in the study had experience of OC and only $12(4.84 \%)$ of the 248 women who developed breast cancer had taken $\mathrm{OC}$, so the sample size was extremely small. Therefore it is difficult to extrapolate the results to other studies where OC use is much higher.

Regarding other risk factors for breast cancer, as pointed out by Anothaisintawee et al (Anothaisintawee et al., 2014), the distribution of disease subtypes according to hormone receptor (i.e. estrogen receptor (ER) and progesterone receptor (PR)) differs between Asian and Caucasian women. In Asian women the ER+ tumor is not as common as in Caucasian women (Wiechmann et al., 2009; Telli et al., 2011; Chuthapisith et al., 2012). Previous studies have shown that ER+ tumors are associated with reproductive history (i.e., age at menarche, parity, and breastfeeding) while ER- tumors are not (Althuis et al., 2004; Tsakountakis et al., 2005). This might also be why breastfeeding history was not a protective factor in this study. Further studies are needed in hormone receptor status, OC use, and breast cancer in Japanese women. Furthermore, similar to the Thai data, a family history of breast cancer was also not a significant risk in the present study.

In this study, an association between OC use and increased breast cancer risk was not observed. Contrary to our expectations, presently taking OC was significantly associated with a lower risk of breast cancer, compared to those women not using OC. However, this may be partly explained by the fact that women at high risk of developing breast cancer may actively chose not to use OC.

There are several other limitations to this study that need to be addressed. Obesity is a well-known risk factor for breast cancer, both in Asian (Mori et al., 2011; Suzuki et al., 2011; Minatoya et al., 2014), and Western populations (Kabat et al., 2014), however, no information on BMI was available in the present study which may have influenced our results. Furthermore, no information was also available for mammography breast density and history of benign breast disease, two other well known risk factors for breast cancer (McCormack and dos Santos Silva, 2006; Ashbeck et al., 2007). Finally, despite our results, great caution must be taken when interpreting them since the average age of the women in this study was $39.6 \mathrm{yrs}$, considerably younger than the average age of 58.8 yrs in Japanese breast cancer patients, which suggests that the follow-up period of the women in this study may have been too short and further long-term prospective studies are necessary.

Despite these limitations, our paper also has some strengths, the greatest being that around $28.8 \%$ of the women in the study used or had previously used OC, which is considerably higher than population-based use. Furthermore, our sample size was large and included women not only from the Tokyo area, but other regions of Japan since most of our participants were privately paying patients coming for a yearly check-up.

In conclusion, this clinic-based case-control study which aimed to clarify the associations between menstrual, familial and reproductive factors and OC use with breast cancer risk in Japanese women found that present use of OC in premenopausal women was associated with a low risk of breast cancer, while no associations were found among past users. Furthermore, breast-feeding did not correlated with the low risk of breast cancer in this study. Increased age, especially being over $40 \mathrm{yrs}$, was a significant risk for breast cancer, which is similar to other Asian data and earlier then for Western women. This suggests that age rather than OC use has a greater effect on breast cancer risk and we observed no increased breast cancer risk in Japanese women taking oral contraceptives at our clinic. However, further long-term prospective studies are necessary.

\section{Acknowledgements}

The authors would like to express their sincere gratitude to Dr. Sharon Hanley for her English editing of the manuscript and Ms. Reiko Nishimoto for all her help with the data input. They would also like to thank all the women who agreed to take part in this study.

\section{References}

Anonymouse (1996). Breast cancer and hormonal contraceptives: collaborative reanalysis of individual data on 53297 women with breast cancer and 100239 women without breast cancer from 54 epidemiological studies. Lancet, 347, 1713-27.

Althuis MD, Fergenbaum JH, Garcia-Closas M, et al (2004). Etiology of hormone receptor-defined breast cancer: a systematic review of the literature. Cancer Epidemiol Biomarkers Prev, 13, 1558-68.

Anothaisintawee T, Teerawattananon Y, Wiratkapun C, et al (2014). Development and validation of a breast cancer risk prediction model for Thai women: a cross-sectional study. Asian Pac J Cancer Prev, 15, 6811-7.

Ashbeck EL, Rosenberg RD, Stauber PM, et al (2007). Benign breast biopsy diagnosis and subsequent risk of breast cancer. Cancer Epidemiol Biomarkers Prev, 16, 467-72.

Caserta D, Ralli E, Matteucci E, et al (2014). Combined oral contraceptives: health benefits beyond contraception. Panminerva Med, 56, 233-44.

Charlton BM, Rich-Edwards JW, Colditz GA, et al (2014). Oral contraceptive use and mortality after 36 years of follow-up in the Nurses' Health Study: prospective cohort study. BMJ, 349, 6356.

Chuthapisith S, Permsapaya W, Warnnissorn M, et al (2012). Breast cancer subtypes identified by the ER, PR and HER-2 status in Thai women. Asian Pac J Cancer Prev, 13, 459-62.

Henderson JT, Sawaya GF, Blum M, et al (2010). Pelvic examinations and access to oral hormonal contraception. Obstet Gynecol, 116, 1257-64.

Kabat GC, Xue X, Kamensky V, et al (2014). Risk of breast, endometrial, colorectal, and renal cancers in postmenopausal women in association with a body shape index and other anthropometric measures. Cancer Causes Control, 26, 
219-29.

Kahlenborn C, Modugno F, Potter DM, et al (2006). Oral contraceptive use as a risk factor $\mathrm{f}$ or premenopausal breast cancer: a meta-analysis. Mayo Clin Proc, 81, 1290-302.

Kawai M, Minami Y, Kuriyama S, et al (2010). Reproductive factors, exogenous female hormone use and breast cancer risk in Japanese: the miyagi cohort study. Cancer Causes Control, 21, 135-45.

Kitamura K (2014), The proposal for increasing of oral contraceptives use. Acta Obst Gynae Jpn, 9, 2131-41.

Marchbanks PA, McDonald JA, Wilson HG, et al (2002). Oral contraceptives and the risk of breast cancer. $N$ Engl J Med, 346, 2025-32.

Matsumoto K, Ohkawa Y, Sasauchi K, et al (2003). A survey on low-dose oral contraceptive transactions at pharmacies. Yakugaku Zasshi, 123, 157-162.

McCormack VA, dos Santos Silva I (2006). Breast density and parenchymal patterns as markers of breast cancer risk: a meta-analysis. Cancer Epidemiol Biomarkers Prev, 15, 1159-69.

Minatoya M, Kutomi G, Shima H, et al (2014). Relation of serum adiponectin levels and obesity with breast cancer: a Japanese case-control study. Asian Pac J Cancer Prev, 15, 8325-30.

Mori M, Masumori N, Fukuta F, et al (2011). Weight gain and family history of prostate or breast cancers as risk factors for prostate cancer: results of a case-control study in Japan. Asian Pac J Cancer Prev, 12, 743-7.

Nishino Y, Minami Y, Kawai M, et al (2014). Cigarette smoking and breast cancer risk in relation to joint estrogen and progesterone receptor status: a case-control study in Japan. Springerplus, 3, 65.

Suzuki R, Iwasaki M, Hara A, et al (2013). Fruit and vegetable intake and breast cancer risk defined by estrogen and progesterone receptor status: the Japan public health center-based prospective study. Cancer Causes Control, 24, 2117-28.

Suzuki R, Iwasaki M, Inoue M, et al (2010). Alcohol consumption-associated breast cancer incidence and potential effect modifiers: the Japan Public Health Centerbased Prospective Study. Int J Cancer, 127, 685-95.

Suzuki R, Iwasaki M, Inoue M, et al (2011). Body weight at age 20 years, subsequent weight change and breast cancer risk defined by estrogen and progesterone receptor status-the Japan public health center-based prospective study. Int $J$ Cancer, 129, 1214-24.

Telli ML, Chang ET, Kurian AW, et al (2011). Asian ethnicity and breast cancer subtypes: a study from the California Cancer Registry. Breast Cancer Res Treat, 127, 471-8.

Tsakountakis N, Sanidas E, Stathopoulos E, et al (2005). Correlation of breast cancer risk factors with HER-2/ neu protein overexpression according to menopausal and estrogen receptor status. BMC Womens Health, 5, 1.

Tsunematsu M, Kawasaki H, Masuoka Y, et al (2013). Factors affecting breast cancer screening behavior in Japanassessment using the health belief model and conjoint analysis. Asian Pac J Cancer Prev, 14, 6041-8.

United Nations (2013), World contraceptive patterns 2013. Available at: http://www.un.org/en/ development/desa/population/publications/pdf/family/ worldContraceptivePatternsWallChart2013.pdf, accessed October18 ${ }^{\text {th }}, 2014$.

Vaisy A, Lotfinejad S, Zhian F (2014). Risk of cancer with combined oral contraceptive use among Iranian women. Asian Pac J Cancer Prev, 15, 5517-22.

Wada K, Nakamura K, Tamai Y, et al (2013). Soy isoflavone intake and breast cancer risk in Japan: from the Takayama study. Int J Cancer, 133, 952-60.
Wiechmann L, Sampson M, Stempel M, et al (2009). Presenting features of breast cancer differ by molecular subtype. Ann Surg Oncol, 16, 2705-10. 